\title{
The use of tranexamic acid to reduce blood loss in uncemented total hip arthroplasty for avascular necrosis of femoral head: a prospective blinded randomized controlled study
}

\author{
Javahir A. Pachore', Vikram Indrajit Shah², Sachin Upadhyay ${ }^{3,4^{*}}$ (D, Kalpesh Shah², Ashish Sheth ${ }^{2}$ and Amish Kshatriya ${ }^{2}$
}

\begin{abstract}
Background: The purpose of this prospective, double-blinded, randomized controlled study is to assess the efficacy of administration of intravenous tranexamic acid (TXA) for reducing blood loss in uncemented total hip arthroplasty (THA) for the treatment of osteonecrosis of femoral head.

Methods: Between April 2012 and March 2014, 73 patients with avascular necrosis of femoral head were treated in our center. The patients were randomized and allocated to study group $(n=36$; treated with TXA) and control group $(n=37)$. Intra- and postoperative blood loss, blood transfusion, and incidence of deep vein thrombosis were assessed. A $p$ value less than 0.05 was considered statistically significant.

Results: The intraoperative, postoperative, and total (clinical method and Gross' formula) blood loss were significantly greater in the control group $(p<0.05)$. On the first, second, and third postoperative days, the levels of hemoglobin and hematocrit were significantly better in the study group $(p<0.05)$. There was a significantly greater number of patients who required blood transfusion in the control group $(p=.027)$. Deep vein thrombosis was not found in either group.
\end{abstract}

Conclusions: A single dose of TXA used preoperatively may minimize intraoperative, postoperative, and total blood loss in uncemented THA for the treatment of osteonecrosis of femoral head, and may not increase the risk of prothrombotic complications.

Keywords: Tranexamic acid, Osteonecrosis, Total hip arthroplasty, Deep vein thrombosis

\section{Background}

Total hip arthroplasty (THA) may cause postoperative blood loss that may necessitate blood transfusion $[1,2]$. However, allogenic reactions due to blood transfusion are possible, which may put the patient at the risk of severe complications, and add more cost to the treatments [3-5]. Several strategies have been devised to reduce perioperative blood loss during THA [6]. The use of

\footnotetext{
* Correspondence: drsachinupadhyay@gmail.com

${ }^{3}$ Department of Orthopaedics, NSCB Medical College, Jabalpur, MP, India

${ }^{4}$ Department of Trauma, Joint Replacement and Minimal Invasive Surgery,

Shalby Hospitals Jabalpur, Jabalpur, Madhya Pradesh, India

Full list of author information is available at the end of the article
}

tranexamic acid (TXA) can reportedly reduce blood loss and thereby decrease blood transfusion after THA $[2,7]$.

TXA is a synthetic derivative of lysine that exerts its antifibrinolytic effect by blocking the lysine binding sites of plasminogen, which ultimately blocks the degradation of fibrin [8]. This process may also potentially enhance the risk of venous thromboembolic events (VTEs) by promoting thrombosis [9]. Most randomized controlled trials evaluating the efficacy of tranexamic acid during THA included cohorts with a diagnosis of osteoarthritis or those with either osteoarthritis or osteonecrosis of femoral head [4, 10-17]. In contrast to Caucasian population, in India total hip arthroplasty is

(c) The Author(s). 2019 Open Access This article is distributed under the terms of the Creative Commons Attribution 4.0 International License (http://creativecommons.org/licenses/by/4.0/), which permits unrestricted use, distribution, and 
more commonly performed for avascular necrosis of hip than for primary osteoarthritis [18]. Compromised subchondral microcirculation and ischemia through distinct underlying pathophysical mechanism leading to osteonecrosis [19]. We found no randomized controlled trial evaluating the efficacy of intravenous tranexamic acid in reducing perioperative blood loss and need for blood transfusions after uncemented THA for a specific diagnosis of osteonecrosis of the femoral head only and this was the aim of our study. We also wanted to find out if there is any high incidence of DVT in this group. We hypothesized that a single pre-incisional dose of intravenous tranexamic acid reduces blood loss associated with uncemented THA for osteonecrosis of femoral head.

\section{Materials and methods}

The institutional review boards of the participating hospitals reviewed the study and approved the protocol. Informed consent was obtained from each patient.

Between April 2012 and March 2014, patients undergoing uncemented THA for osteonecrosis of femoral head were considered for the study. Participants were recruited into the study, and randomized into two groups: treatment and control group. Study was designed as a 1:1 case control study. Our eligibility criteria were unilateral involvement; avascular necrosis of femoral head with moderate to severe arthritis; hip pain interfering with daily living; and primary THA. Patients were excluded if they had one of the following: 1) mild arthritis, rheumatoid arthritis, post-traumatic arthritis; 2) thrombocytopenia (platelet count $<100,000 /$ $\mathrm{mm} 3$; 3) anaemia (hemoglobin $(\mathrm{Hb})<11 \mathrm{~g} \%$; packed cell volume $<33 \%) ; 4$ ) under thrombolytic or anticoagulant therapy; 5) haemorrhage or haemorrhagic diathesis; 6) hypersensitivity to tranexamic acid; 7) a history of administration of NSAIDs within 1 week; 8) a history of deep vein DVT/pulmonary embolism (PE); 9) renal dysfunction; 10) major illness and health condition such as severe cardiac disorders; 11) previous ipsilateral hip surgery such as synovectomy, decompression, grafting, osteotomy, and fracture fixation; 12) body mass index $(\mathrm{BMI})>30$; 13) decline to participate; 14) unwilling to receive any surgical intervention; 15) bilateral involvement; and 16) osteonecrosis secondary to sickle cell anaemia or renal transplant.

Sample size was estimated using formula of simple random sampling for infinite population. Assumptions were considered based on the difference in mean volume of blood loss in treatment [16]. The power analysis determined that the study comprising a minimum of 72 patients required $95 \%$ confidence intervals $(5 \%$ a), $80 \%$ power, and 0.1 absolute precision (marginal error). Out of 102 patients, 74 were selected, randomized, and allocated to a study group $(n=37)$ and a control group $(n=37)$. The consort flow chart for the study is shown in Fig. 1.

\section{TXA administration}

Patients in study group and control group received TXA or nothing, respectively, which were packaged in envelopes marked with numbers. The envelopes were randomly drawn by a third person who did not participate in the treatments and were blinded to the sample envelope numbers. The envelopes were handled to the anaesthetists. The surgeons and assessors were blinded. The sample code was not broken until the study was completed. Patients in the study group received a single dose of intravenous TXA $(10 \mathrm{mg} / \mathrm{kg}$ body weight, maximum dose: $1 \mathrm{~g}) 15 \mathrm{~min}$ prior to skin incision. Patients in the control group did not receive any drug. All patients were operated on by a single experienced surgeon in lateral position using posterior approach thus ensuring a consistent surgical technique. Intraoperative haemostasis was completely achieved using electrocoagulation. All patients received spinal anaesthesia for surgery by the same anaesthetist. A closed suction drainage system was used in all cases and was removed in $48 \mathrm{~h}$.

\section{Blood loss calculation}

Intraoperative blood loss was measured using an electric weighing scale with an accuracy of $0.1 \mathrm{mg}$ (Alexandra Scale Pvt. Ltd., Gujarat, India). All blood-stained mops and the blood in the suction cylinders were included in the blood loss. The postoperative blood loss was calculated using two methods. First, the blood loss was determined based on the blood collected from the suction drain 12, 24, and $48 \mathrm{~h}$ after surgery. Second, the blood loss was estimated based on hematocrit balance using Gross' formula [20], which included the blood loss of extravasation in the tissues. Gross' formula are as follows:

$$
\begin{aligned}
\text { Estimated blood loss }= & \text { Estimated blood volume } \\
& \times(\text { initial hematocrit }- \text { final hematocrit }) \\
& / \text { mean hematocrit }
\end{aligned}
$$

$$
\begin{aligned}
\text { Estimated blood volume }= & \text { body weight }(\mathrm{kg}) \\
& \times 70 \mathrm{ml} / \mathrm{kg}
\end{aligned}
$$

The total blood loss (clinical) was determined by adding intraoperative and postoperative blood loss.

\section{Laboratory data collection}

The levels of hemoglobin and hematocrit concentration, as well as bleeding time, clotting time, prothrombin time, and activated partial thromboplastin time, were tested at admission as the baseline. The parameters on the first and second postoperative days were also obtained. A uniform blood transfusion protocol was used in both groups. Postoperative blood transfusion was given if the level of haematocrit was less than $27 \%$ of normal range. Intraoperative, postoperative, and total 


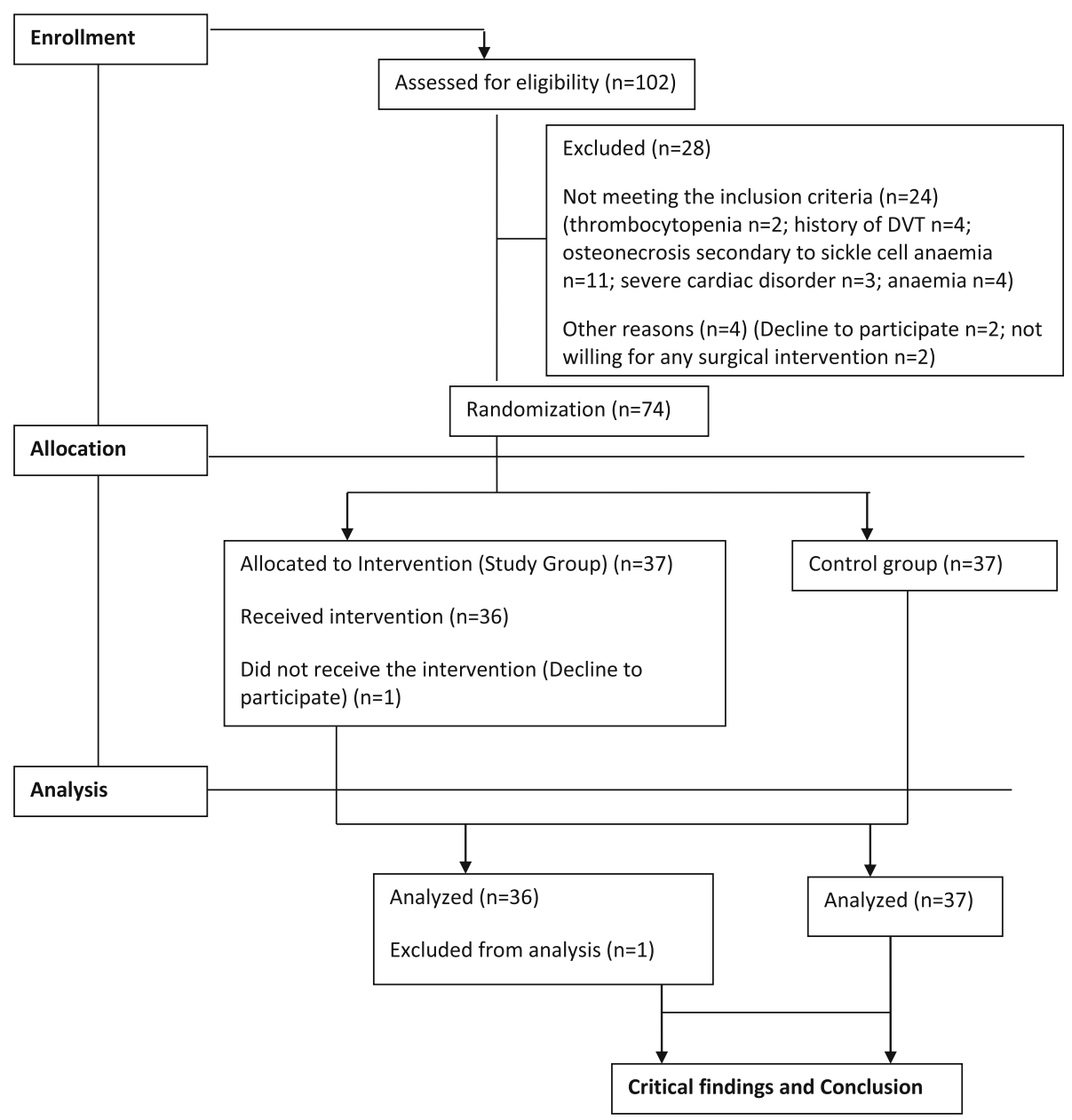

Fig. 1 Consort flow chart

blood loss (both clinical method and Gross' formula method were used) were the primary analytic focus.

\section{Patient managements}

Doppler ultrasound was performed prior to surgery and on the 5th postoperative day to rule out DVT. All patients were given anti- thromboembolic stockings for 6 weeks. Chemoprophylaxis for DVT and PE was not used. All patients were ambulated partial weight bearing with support postoperatively as soon as they were comfortable for the first 3 weeks, which was followed by full weight bearing thereafter.

\section{Statistical analysis}

Demographic data were presented as mean \pm standard deviation (SD) and range. During the analysis, numerically-coded categorical variables were cross tabulated, and Chi square or Fisher's exact test was applied as required. If the frequency was less than five, a Fisher's exact $p$ value was used; and Pearson's Chi square tests were used for other analyses. Student $t$ test was used to test the differences between two independent means. The Shapiro-Wilk test was used to test normality. When the variable significantly deviated from a normal distribution, a log transformation was performed for statistical comparison. Analyses were performed using a s tatistical software package (SPSS for Windows software, version 22.0, SPSS, Inc., Chicago, IL, USA).

\section{Results}

There were no significant differences between the two groups with regard to demographic or preoperative characteristics $(p>0.05)$ (Table 1). Intraoperative and postoperative blood loss, changes in the levels of hemoglobin and hematocrit, the amount of blood transfusion and complications are shown in Table 2 . In the study group, one patient who refused to receive allocated intervention after randomization was excluded from the final analysis. A total of 73 patients were available for final analysis.

The mean between-group discrepancies in intraoperative blood loss, postoperative blood loss, total blood loss 
Table 1 Patient demographics and preoperative characteristics

\begin{tabular}{llll}
\hline Characteristics & $\begin{array}{l}\text { Study group } \\
\text { (Mean } \pm \text { SD) }(n=37)\end{array}$ & $\begin{array}{l}\text { Control group } \\
\text { (Mean } \pm \text { SD) }(n=37)\end{array}$ & $p$ value \\
\hline Age (years) & $48.5 \pm 13.5$ & $52.2 \pm 11.4$ & 0.2 \\
Sex (Male: female) & $24: 13$ & $23: 14$ & 0.8 \\
BMl & $26.2 \pm 1.5$ & $26.8 \pm 1.6$ & 0.1 \\
Pre-op Hb (g/100 mL) & $13.2 \pm 1.5$ & $13.3 \pm 1.4$ & $36.7 \pm 3.3$ \\
Pre-op Hct (\%) & $36.9 \pm 3.8$ & & 0.7 \\
Cause of osteonecrosis (No. of patients) & & 10 & 0.7 \\
$\quad$ Steroid intake & 11 & 4 \\
$\quad$ Alcoholism & 6 & 23 \\
$\quad$ Idiopathic & 20 &
\end{tabular}

$S D$ standard deviation, $B M I$ body mass index, $H b$ haemoglobin, $H c t$ hematocrit

(clinical), and total blood loss (Gross' formula) were 113 $\mathrm{mL}, 152 \mathrm{~mL}, 257 \mathrm{~mL}$, and $363 \mathrm{~mL}$, respectively.

We found that there were significant differences between the two groups with regard to the amount of intraoperative blood loss $(p<0.0001)$ and postoperative drainage $(p<0.0001)$, and total (clinical method and Gross' formula) blood loss $(p<0.0001)$. We also found significant differences with regard to the levels of hemoglobin concentration immediately after surgery $(p=0.0106)$, and on the first postoperative day $(p=0.0019)$, and on the second postoperative $(p<0.0001)$ day. The levels of hematocrit concentration were also significantly different $(p<0.05)$. The decreased amount of hemoglobin and hematocrit concentration on the first $(p<0.0001 ; p<$ $0.0001)$ and second $(p<0.0001 ; p=0.0002)$ postoperative days were significantly different. There were significant difference with regard to the number of patients who received blood transfusion $(p=.027)$. Neither deep venous clots nor PEs happened, and nor other complications took place in both groups.

Table 2 Comparison of intra- and postoperative characteristics between the two groups

\begin{tabular}{|c|c|c|c|}
\hline Parameters & $\begin{array}{l}\text { Study group } \\
(n=36)\end{array}$ & $\begin{array}{l}\text { Control group } \\
(n=37)\end{array}$ & $p$ value \\
\hline$\overline{O p e r a t i v e ~ t i m e ~(m i n u t e s) ~}{ }^{a}$ & $125.8 \pm 10.2$ & $128.8 \pm 9.4$ & 0.195 \\
\hline Intraoperative blood loss (mL) & $230.9 \pm 41.6$ & $344 \pm 144$ & $<0.0001$ \\
\hline Drain $(\mathrm{mL})-12 \mathrm{~h}$ & $115 \pm 31.2$ & $168 \pm 51.3$ & $<0.0001$ \\
\hline $24 \mathrm{~h}$ & $74.2 \pm 20.4$ & $136 \pm 8.5$ & $<0.0001$ \\
\hline $48 \mathrm{~h}$ & $61 \pm 18.6$ & $98.6 \pm 35.6$ & $<0.0001$ \\
\hline Total blood loss (clinical method) & $481 \pm 43.9$ & $737.6 \pm 137.8$ & $<0.0001$ \\
\hline Total blood loss- Gross' formula & $484.2 \pm 260.9$ & $847 \pm 374.5$ & $<0.0001$ \\
\hline \multicolumn{4}{|l|}{ Post-op Hb } \\
\hline Day1 & $12.1 \pm 1.4$ & $11.3 \pm 1.2$ & $=0.0106$ \\
\hline Day 2 & $11.5 \pm 1.1$ & $11 \pm 1$ & $=0.046$ \\
\hline \multicolumn{4}{|l|}{ Drop in $\mathrm{Hb}$} \\
\hline Day1 & $1.1 \pm 0.4$ & $2 \pm 0.7$ & $<0.0001$ \\
\hline Day 2 & $1.8 \pm 1.1$ & $2.4 \pm 0.5$ & $=.004$ \\
\hline \multicolumn{4}{|l|}{ Post-op Hct } \\
\hline Day 1 & $34.1 \pm 3.4$ & $31.5 \pm 3.5$ & $=0.0019$ \\
\hline Day 2 & $33.4 \pm 2.5$ & $31.1 \pm 1.9$ & $<0.0001$ \\
\hline \multicolumn{4}{|l|}{ Drop in Hct } \\
\hline Day 1 & $2.7 \pm 1.8$ & $5.2 \pm 2.1$ & $<0.0001$ \\
\hline Day 2 & $3.4 \pm 1.9$ & $5.5 \pm 2.6$ & 0.0002 \\
\hline Blood transfusion (no. of patients) ${ }^{b}$ & 1 & 7 & .027299 \\
\hline Complications & None & None & 1.000 \\
\hline
\end{tabular}

$\mathrm{Hb}$ Haemoglobin, Hct Haematocrit, ${ }^{a}$ Time from induction tol wound closure, ${ }^{\mathrm{b}}$ each patient was given one unit of whole blood transfusion 


\section{Discussion}

We found TXA can effectively decrease perioperative bleeding and the need for blood transfusions after THA. In a meta-analysis, Zhou et al. [21] found the total blood loss was $305 \mathrm{~mL}$, intraoperative blood was $86 \mathrm{~mL}$, and postoperative blood loss was $177 \mathrm{~mL}$ in THA. Another meta-analysis conducted by Huang et al. [7] found that TXA decreased the total blood loss of $389 \mathrm{~mL}$. However, our study included patients undergoing THA for osteonecrosis of femoral head only. The blood loss during THA for osteonecrosis of femoral head is likely to be different from THA for osteoarthritis due to the differences in the degree of marrow edema and synovitis [22]. Clave et al. [11] and Yamasaki et al. [15] reported similar intraoperative blood loss but reduced postoperative blood loss in the tranexamic acid treatment group as compared to the control group. This is in contrast to our findings of reduction in both intraoperative and postoperative blood loss in the tranexamic acid group as compared to the control. Furthermore, they included patients with osteoarthritis only in their study while our study included osteonecrosis of femoral head. Johansson et al. [4], who included patients with osteoarthritis only but performed cemented THAs, also showed no significant difference in intraoperative blood loss in the tranexamic acid group. Rajesparan et al. [6] and Husted et al. [17], with predominantly osteoarthritic patients in their studies, also reported no significant difference in the intraoperative blood loss between tranexamic acid and control groups. It is likely that the indication for THA (osteoarthritis vs. osteonecrosis) might be responsible for the reportedly different pattern of blood loss because the factors, like marrow edema and synovitis, that are likely to influence blood loss, are different in the two pathologies. We administered a single dose of tranexamic acid 15 minutes prior to skin incision. However, the reduction in blood loss was seen intraoperatively and postoperatively up-to $48 \mathrm{~h}$. Surgical trauma and venous stasis causes release of tissue plasminogen activator which initiates fibrinolysis that lasts for an hour $[6,12]$. However, the pre-incisional administration of tranexamic acid inhibits fibrinolysis by binding itself to plasminogen. The reduction in intraoperative blood loss as seen in our study might be explained by this effect of tranexamic acid on the coagulation pathway. In our own clinical practice, we have observed reduced intraoperative bleeding and better surgical field in patients receiving tranexamic acid prior to incision. The fibrinolytic inhibition that occurs at about $24 \mathrm{~h}$ is due to an increased release of plasminogen activator inhibitor which inactivates tissue plasminogen activator. The sustained effect on reduction in blood loss postoperatively may be in part due to fibrinolytic inhibition and in part due to clot stabilization. This reduces postoperative blood loss after THA in patients receiving tranexamic acid and the result has been widely reported $[4,6,11,13$, $15,17]$. The two groups in our study were similar (Table 1 ). Factors that are likely to influence blood loss like age, BMI, gender, and pathology were similar between the two groups. The preoperative $\mathrm{Hb}$ and Hct were also similar between the two groups. All patients underwent uncemented THA using the same approach by the same surgeon and anaesthetist to ensure consistency. Both the surgeon and the assessor were blinded to the randomization. Thus, all the factors that are likely to cause bias were controlled. An intravenous dose of $10 \mathrm{mg} / \mathrm{kg}$ reportedly maintained therapeutic plasma concentration of tranexamic acid for up to 3 hours [23] and hence this dose was chosen in our study. A higher dose was avoided due to theoretical concern of prothrombotic complications. We used a single dose instead of multiple ones since several studies have confirmed the efficacy of a single dose in reducing blood loss during THA [4, 6]. Benoni et al. have shown that tranexamic acid administered at the end of surgery has no effect on reduction of postoperative blood loss and hence we administered it 15 min prior to incision [24].

Our study focused on a homogenous group of patients undergoing uncemented THA unlike previous studies $[6,12,17]$ that have included cemented, uncemented, and hybrid THAs which may behave differently as far as postoperative bleeding is concerned. Uncemented THA behaves differently from cemented or hybrid THA as the femoral canal and possibly the acetabular bony beds are closed off by cement, and the pressurization of cement has a ceasing effect on blood loss from intramedullary circulation. Therefore, postoperative bleeding tends to be higher in the uncemented THA than in the cemented THA due to spontaneous bleeding from intramedullary circulation [15]. With the use of tranexamic acid, there is a concern that it may induce a hypercoagulable state [25]. An interesting feature of our study was the lack of use of chemoprophylaxis against DVT/ PE. Anti-thromboembolic stockings and early ambulation were encouraged to prevent DVT/ PE. Most studies evaluating the role of tranexamic acid in THA have used chemoprophylaxis against DVT/ PE and have reported that the use of tranexamic acid was not associated with a significant increase in the risk of DVT/PE $[4,10,26]$. Since the chemoprophylaxis may counter the hypercoagulability effect of tranexamic acid, it is a confounding factor. However, by not using chemoprophylaxis against DVT/PE, our study conclusively shows that the use of tranexamic acid is not associated with an increased risk of DVT/ PE. The preoperative and postoperative day 5 screening for DVT using venous Doppler ensured that asymptomatic DVTs were not missed. The limitation of our study was the small sample size that may affect the results of the present trial. A multicenter, randomized study with large sample size may yield more statistically significant results. 


\section{Conclusion}

The present analysis needs to be put in the perspective of the rapidly increasing number of hip arthroplasties being performed each year. Our findings suggest that a single pre-incisional dose of tranexamic acid results in a statistically significant and clinically meaningful reduction in intraoperative, postoperative, and total blood loss from uncemented THA for osteonecrosis of femoral head without increasing the risk of prothrombotic complications.

\section{Abbreviations}

BMI: Body Mass Index; DVT: Deep Vein Thrombosis; Hb: Haemoglobin; NSAIDs: Nonsteroidal Anti-inflammatory Drugs; PE: Pulmonary Embolism; THA: Total Hip Arthroplasty; TXA: Tranexamic Acid; VTE: Venous ThromboEmbolism

\section{Acknowledgements}

We acknowledge all the patients who participated in the study, nursing, paramedical staff. We also acknowledge the contribution of entire research team.

\section{Authors' contributions}

JAP (Conceptualization; Data curation; Investigation; Methodology; Supervision; Writing -review \& editing). VIS(Resources). SU (Conceptualization; Data curation; Formal analysis; Investigation; Methodology; Resources; Supervision; Validation; Visualization; Writing review \& editing). KS (Resources). AS (Resources). AK (Resources). All authors read and approved the final manuscript.

\section{Funding}

Not applicable

\section{Availability of data and materials}

The data that support the findings of this study are available from [Shalby Hospitals India] but restrictions apply to the availability of these data, which were used under license for the current study, and so are not publicly available. Data are however available from the authors upon reasonable request and with permission of [Shalby Hospitals India]

\section{Ethics approval and consent to participate}

The study was approved by the Scientific Review Committee and the institutional review board of the participating Health Service. Written informed consent (about the surgical technique, risks and potential complications) was provided according to the Declaration of Helsinki and obtained from all participating patients.

\section{Consent for publication}

Informed consent was obtained from the patients for publication of their case records for providing evidence-based scientific literature for further research.

\section{Competing interests}

The authors declare that they have no competing interests.

\section{Author details}

1 Department of Hip Arthroplasty, Shalby Hospitals, Ahmedabad, Gujarat, India. ${ }^{2}$ Department of Knee and Hip Arthroplasty, Shalby Hospitals, Ahmedabad, Gujarat, India. ${ }^{3}$ Department of Orthopaedics, NSCB Medical College, Jabalpur, MP, India. ${ }^{4}$ Department of Trauma, Joint Replacement and Minimal Invasive Surgery, Shalby Hospitals Jabalpur, Jabalpur, Madhya Pradesh, India.
Received: 29 May 2019 Accepted: 22 October 2019

Published online: 21 November 2019

\section{References}

1. Melvin JS, Stryker LS, Sierra RJ. Tranexamic Acid in Hip and Knee Arthroplasty. J Am Acad Orthop Surg. 2015;23:732-40.

2. Kim C, Park SS, Davey JR. Tranexamic acid for the prevention and management of orthopedic surgical hemorrhage: current evidence. J Blood Med. 2015;6:239-44.

3. Kleinman S, Chan P, Robillard P. Risks associated with transfusion of cellular blood components in Canada. Transfus Med Rev. 2003;17:120-62.

4. Johansson T, Pettersson LG, Lisander B. Tranexamic acid in total hip arthroplasty saves blood and money: a randomized, double-blind study in 100 patients. Acta Orthop. 2005;76:314-9.

5. Blumberg N, Kirkley SA, Heal JM. A cost analysis of autologous and allergenic transfusions in hip-replacement surgery. Am J Surg. 1996;171:324-30.

6. Rajesparan K, Biant LC, Ahmad M, Field RE. The effect of an intravenous bolus of tranexamic acid on blood loss in total hip replacement. J Bone Joint Surg Br. 2009;91:776-83.

7. Huang F, Wu Y, Yin Z, Ma G, Chang J. A systematic review and metaanalysis of the use of antifibrinolytic agents in total hip arthroplasty. Hip Int. 2015;25:502-9.

8. Dunn CJ, Goa KL. Tranexamic acid: a review of its use in surgery and other indications. Drugs. 1999;57:1005-32.

9. $\quad \mathrm{Ng}$ W, Jerath A, Wasowicz M. Tranexamic acid: a clinical review. Anaesthesiol Intensive Ther. 2015:47:339-50.

10. Imai N, Dohmae Y, Suda K, Miyasaka D, Ito T, Endo N. Tranexamic acid for reduction of blood loss during total hip arthroplasty. J Arthroplast. 2012;27: 1838-43.

11. Clave A, Fazilleau F, Dumser D, Lacroix J. Efficacy of tranexamic acid on blood loss after primary cementless total hip replacement with rivaroxaban thromboprophylaxis: a case-control study in 70 patients. Orthop Traumatol Surg Res. 2012;98:484-90.

12. Singh J, Ballal MS, Mitchell P, Denn PG. Effects of tranexamic acid on blood loss during total hip arthroplasty. J Orthop Surg. 2010;18:282-6.

13. Claeys MA, Vermeersch N, Haentjens P. Reduction of blood loss with tranexamic acid in primary total hip replacement surgery. Acta Chir Belg. 2007;107:397-401

14. Niskanen RO, Korkala OL. Tranexamic acid reduces blood loss in cemented hip arthroplasty: a randomized, double-blind study of 39 patients with osteoarthritis. Acta Orthop. 2005;76:829-32.

15. Yamasaki S, Masuhara K, Fuji T. Tranexamic acid reduces blood loss after cementless total hip arthroplasty-prospective randomized study in 40 cases. Int Orthop. 2004;28:69-73.

16. Benoni G, Fredin H, Knebel R, Nilsson P. Blood conservation with tranexamic acid in total hip arthroplasty: a randomized, double-blind study in 40 primary operations. Acta Orthop Scand. 2001;72:442-8.

17. Husted H, Blond L, Sonne-Holm S, Holm G, Jacobsen TW, Gebuhr P. Tranexamic acid reduces blood loss and blood transfusions in primary total hip arthroplasty: a prospective randomized double-blind study in 40 patients. Acta Orthop Scand. 2003;74:665-9.

18. Pachore JA, Vaidya SV, Thakkar CJ, Bhalodia HP, Wakankar HM. ISHKS joint registry: a preliminary report. Indian J Orthop. 2013;47:505-9.

19. Shah KN, Racine J, Jones LC, Aaron RK. Pathophysiology and risk factors for osteonecrosis. Curr Rev Musculoskelet Med. 2015:8:201-9.

20. Gross JB. Estimating allowable blood loss: corrected for dilution. Anesthesiology. 1983;58:277-80.

21. Zhou XD, Tao LJ, Li J, Wu LD. Do we really need tranexamic acid in total hip arthroplasty? A meta-analysis of nineteen randomized controlled trials. Arch Orthop Trauma Surg. 2013;133:1017-27.

22. Song JH, Han SK, Lee KH, Lee JM, Lee KH. Comparison of perioperative blood loss in primary non-cemented Total hip Arthroplasty for rapidly destructive Coxarthrosis and osteonecrosis of the femoral head. Hip Pelvis. 2015;27:141-5

23. Jansen AJ, Andreica S, Claeys M, D'Haese J, Camu F, Jochmans K. Use of tranexamic acid for an effective blood conservation strategy after total knee arthroplasty. Br J Anaesth. 1999:83:596-601.

24. Benoni G, Lethagen S, Nilsson P, Fredin H. Tranexamic acid, given at the end of the operation, does not reduce postoperative blood loss in hip arthroplasty. Acta Orthop Scand. 2000;71:250-4. 
25. Reid RW, Zimmerman AA, Laussen PC, Mayer JE, Gorlin JB, Burrows FA. The efficacy of tranexamic acid versus placebo in decreasing blood loss in pediatric patients undergoing repeat cardiac surgery. Anesth Analg. 1997:84:990-6.

26. Ekbäck G, Axelsson K, Ryttberg L, Edlund B, Kjellberg J, Weckström J, Carlsson O, Schött U. Tranexamic acid reduces blood loss in total hip replacement surgery. Anesth Analg. 2000;91:1124-30.

\section{Publisher's Note}

Springer Nature remains neutral with regard to jurisdictional claims in published maps and institutional affiliations.

Ready to submit your research? Choose BMC and benefit from:

- fast, convenient online submission

- thorough peer review by experienced researchers in your field

- rapid publication on acceptance

- support for research data, including large and complex data types

- gold Open Access which fosters wider collaboration and increased citations

- maximum visibility for your research: over $100 \mathrm{M}$ website views per year

At $\mathrm{BMC}$, research is always in progress.

Learn more biomedcentral.com/submissions 